DIGITALCOMMONS @WAYNESTATE -
Michigan Journal of Counseling:

Research, Theory and Practice

Volume 35 | Issue 2

Article 3

9-1-2008

\title{
Cultural Variations in Parenting and Implications for the Counseling Professional
}

Le'Ann L. Solmonson

Stephen F. Austin State University, 1solmonson@sfasu.edu

Follow this and additional works at: https://digitalcommons.wayne.edu/mijoc

\section{Recommended Citation}

Solmonson, L. L. (2008). Cultural Variations in Parenting and Implications for the Counseling Professional, Michigan Journal of Counseling, 35(2), 12-19. doi:10.22237/mijoc/1220227320

This Article is brought to you for free and open access by the Open Access Journals at DigitalCommons@WayneState. It has been accepted for inclusion in Michigan Journal of Counseling: Research, Theory and Practice by an authorized editor of DigitalCommons@WayneState. 


\section{Cultural Variations in Parenting and Implications for the Counseling Professional}

Le'Ann L. Solmonson, Ph.D., LPC-S, CSC

\section{Stephen F. Austin State University}

Contact the author at

Isolmonson@sfasu.edu

In a culturally diverse society, counselors are faced with providing effective treatment that is culturally responsive and meets the needs of the client. Counselors have an ethical obligation to understand and include the client's culture in treatment decision-making. Parenting norms in the United States are based upon the Western culture and do not apply to all cultural groups. This paper looks specifically at cultural differences in parenting practices among four cultural groups: African Americans, Asians, Hispanics, and European Americans. Implications for practice are provided for the counseling professional.

Key Words: Parenting styles, Cultural variations, Multicultural, Professional counselor ulture can be defined in words that we all understand, and yet can be the source of many misunderstandings. Counselors working in the pluralistic society of today are faced with the challenge of understanding the impact of culture on the counseling process. Counselors have an ethical obligation to know, understand, and include their client's cultural background in order to provide an appropriate counseling experience (Dana, 1998; Webb, 2001).

This article will focus on different cultural approaches to parenting and the implications for the field of counseling. The cultures that will be compared include African American, Asian, Hispanic, and European American or Caucasian. Much research has been done on this topic; however, it is not without controversy or contradictions. Some of the issues that contribute to the controversy include the impact of acculturation on minority populations, Western or European American influence in determining what is appropriate parenting often fails to account for socio-economic differences in sample populations (Jambunathan, Burts, \& Pierce, 2000; Chao, 1994; Stewart, Bond, Kennard, Ho \& Zaman, 2002; Ferrari, 2002).

\section{African Americans}

African Americans have a unique heritage that separates them from any other ethnic group. Other groups have come to the United States to escape oppression and obtain more freedom. African Americans were brought to this country to live a life of slavery and have a history of inequality, which influences parental socialization and group values. African American parents tend to operate from a stricter, more authoritarian style in order to prepare their children for living in an environment filled with racial bias and discrimination (McAdoo, 2001; Jambunathan, Burts \& Pierce, 2000). It is believed this will help children to develop the necessary coping skills to survive in an environment characterized by racism.

According to Mosby, Rawls, Meehan, Mays \& Pettinari (1999), African Americans have a higher incidence of utilizing physical discipline as an integral part of child rearing, but have strict guidelines for its administration to prevent abuse. This research was concerned with the overrepresentation of African American children in child protective systems based upon the use of physical punishment and the unwillingness of many African 
American parents to alter their disciplinary strategies. The authors utilized narrative interviews with African American elders who served as parenting mentors in order to better understand their justification for the use of physical punishment. The narratives suggested strict guidelines for the administration of physical punishment in order to prevent abuse. These guidelines included the elements of nurturing and teaching the child why the discipline is being administered. The elders suggested that children who are not disciplined are unruly and out of control. The unruly behavior is more likely to result in the parent raising their voice and speaking inappropriately to the child. The elders all agreed that verbal abuse is far more detrimental to the child than appropriately administered physical discipline. Ferrari (2002) supports the research regarding higher incidence of physical discipline among this population. However, the same study also reports a high level of nurturing behaviors among African American parents.

There are common generalizations found through the literature regarding the values of African Americans. They report that the culture values familism, which emphasizes dependency on, sense of obligation to, and responsibility for others. Others are defined as the family unit, as well as the greater community. Extended family members are often involved in child rearing and frequently live in the same house or in close proximity. Supportive social networks consist of family, friends, neighbors, and church members and provide emotional and financial support (McAdoo, 2001). Cultural patterns also include respect for elders and authority, a strong work ethic, emphasis on achievement, strong religious background, and freedom of expression (Julian, McKenry \& McKelvey, 1994; Ferrari, 2002; Jambunathan, Burts \& Pierce, 2000).

African American children are expected to assume responsibility for self-care at an earlier age than children in other cultural groups. Children are also expected to be responsible for personal feelings and to participate in decision-making. Parents provide high levels of support in order to facilitate the development of the skills (Jambunathan, Burts \& Pierce, 2000). There are inconsistencies in the research regarding communication by African American parents. As reported by Jambunathan et al., (2002), Field and Widmayer (1981) suggest a lower rate of verbal communication with children; however, Hale-Benson (1986) found a higher rate of non-verbal communication. Jambunathan et al. also reported Zeskind's (1983) findings of a slower response time to infant cries by
African American mothers and higher use of pacifiers or physical stimulation to comfort the crying infant.

Implications for the Counseling Professional. African American families are more likely to seek assistance from within their support system prior to going outside. Women often initiate the treatment process and couples typically seek help due to child-focused issues (Hines \& Franklin, 1996). Families seeking counseling are frequently at a crisis point and may view it as a last resort. They may enter the counseling relationship with suspicion and anxiety based upon previous experience with social service agencies. In addition, there is a stigma associated with seeking outside treatment. These factors make it necessary for the counselor to quickly establish therapeutic rapport, educate the family about the treatment process, and provide explanations for the necessity of treatment (Blue \& Griffith, 2001). Communication of respect is essential and acknowledgment of cultural differences may be necessary (Hines \& Franklin).

Because the church is often the center of the African American community, and the clergy are major leaders in the community, counselors should recognize and utilize this significant influence. Richardson and June (2006) suggest that establishing alliances and partnerships with clergy can facilitate a more positive relationship with individuals within the community. The misconception that African American clergy feel threatened by and hold unfavorable attitudes toward mental health professionals was disputed by Richardson (1991). Richardson and June purport "failure to consider the issues of religion and spirituality in counseling, especially when they play such an important role in the lives of many African Americans, undoubtedly results in less than successful outcomes" (p.115). By working in conjunction with clergy, counselors can foster the social, spiritual, and psychological well being of the African American community.

Single mothers and economic disadvantage have a higher occurrence among African Americans than other ethnic groups (McAdoo, 2001). The additional stress this places on the role of parenting should be considered in dealing with these clients. If fathers are not involved in the family's life, it would be important to determine if there is another significant male figure that should be included in therapy. Eldest sons, uncles, or cousins will often try to fill the father figure in families with absent fathers. Among intact families, the father may be unavailable for treatment due to working multiple 
jobs (McAdoo). Dependent upon the current stressors of the family, counselors may have to assist families in navigating the bureaucratic process of obtaining social services.

\section{Asians}

The Asian ethnic group includes populations from China, Taiwan, Japan, Korea, Vietnam, Indonesia, Philippines, and others. There is a high level of diversity among the group dependent upon the country of origin, the level of acculturation and assimilation into the Western culture, religious affiliation, and reasons for immigration (Jambunathan, Burts \& Pierce, 2000). Traditional Asian families have a patriarchal structure emphasizing filial piety characterized by a strong value for family. Filial piety emphasizes a sense of duty, obligation, respect, and high esteem for elders as demonstrated through obedience. Family ties and dependences are stressed, and individual goals are deemphasized. Cultural tradition includes a hierarchical system with men and elders having higher status than women, youth, and children (Chao, 1994).

Mothers assume the major responsibility for child rearing and are extremely attentive during the preschool years. Asian mothers are very devoted and exhibit high levels of self sacrifice to meet the needs of the children (Lee, 1996). They are more permissive with younger children and demonstrate a high level of warmth and responsiveness. Mothers closely supervise their children and seldom leave them alone. Disciplinary techniques with younger children are nonphysical, but maintain a high level of control. The techniques include verbal and physical redirection and close proximity. Mothers also utilize a sense of family obligation and shame and guilt to encourage compliance in the child (Chao, 1994, Jambunathan, Burts \& Pierce, 2000).

As a child enters school, discipline becomes stricter, and parenting becomes shared by both parents using an authoritarian style. Research (Darling, 1999, Baumrind, 1991) indicates that children of authoritarian parents are more likely to have moderate school success, poor social skills, lower self esteem, and higher levels of depression. However, the Asian parenting style does not have the same behavioral outcomes in Asian children as the authoritarian style has in European American children (Chao, 1994). The cultural value of strict obedience in children is not seen as domination, but as an organization style to enable the family system to operate smoothly (Stewart, Bond, Kennard, Ho \& Zeman, 2002).
Asian families have a strong work ethic and place high value on academic achievement. Independence in achievement is encouraged, where interdependence in relationships is expected (Julian, McKenry \& McKelvey, 1994). Children are expected to exhibit self-control, get along well with others, and conform to societal expectations for appropriate behavior. Overall, the Asian culture values self discipline over external controls. Guilt and shame are both parenting techniques used (Jambunathan, Burts \& Pierce, 2000). Asian parents typically do not reward children for behavior that is expected. Failure brings shame on the family and causes them to lose respect in the community (Lee, 1996).

\section{Implications for the Counseling Professional. Similar} to the African American culture, Asians are more inclined to seek assistance from within the family system before turning to professional treatment (Lee, 1996). Due to the cultural value of saving face, it is often difficult to disclose personal or family problems to an outsider. In addition, discussion of emotions or psychological disturbances is often viewed as a lack of will and the inability to exhibit self control (Dana, 1998). Psychological issues typically are reported in the context of physical complaints. When Asian families present for treatment, it is preferable that it be short term, goal oriented, and result in a decline in problems (Lee, 1997). Extended family may need to be included in the treatment plan.

The counselor must be cognizant of the value system stressing harmony, with group needs superseding individual needs. Treatment goals need to be culturally responsive, rather than determined by the standards of Western culture (Lee, 1997). Due to the importance of respect for authority, Asian families may be more comfortable with a formal relationship and communication style.

A common issue for families presenting for treatment is a culture clash between generations. The longer an individual has been a part of the Western culture, the more likely they are to show an increase in acculturation. Children and adolescents begin to exhibit Western values and/or behaviors, which may cause stress within the family. The counselor is faced with a challenge of assisting the parents in maintaining their cultural values and identity, while addressing the needs of the child or adolescent. As is true for working with all families, mediation, negotiation, and compromise can be used to resolve the conflict, but must be done from a culturally 
responsive mindset. Educating parents about the norms and values of the new culture will assist the family in establishing acceptable standards for coexisting within the Western culture (Lee, 1997; Lee, Blando, Mizelle \& Orozco, 2007).

\section{Hispanics}

In the United States, the Hispanic ethnic group is comprised primarily of individuals from Mexico, Puerto Rico, Cuba, and Central and South America. Similar to Asians, there is a large variation in the group dependent upon economic status, country of origin, educational level, age, common issue for families presenting for treatment is a culture clash between generations...Children and adolescents begin to exhibit Western values and/or behaviors which may cause stress within the family. The counselor is faced with a challenge of assisting the parents in maintaining their cultural values and identity, while addressing the needs of the child or adolescent. As is true for working with all families, mediation, negotiation, and compromise can be used to resolve the conflict, but must be done from a culturally responsive mindset. assume sameness of the entire culture. Like African Americans, Hispanics have dealt with oppression, discrimination, and marginalization. SimilartoAsians, Hispanics are at different levels of assimilation and acculturation. These factors need to be taken into account when working with a Hispanic family. In order to respect the authority of the parent, it is important for counselors to investigate the parents' desire for the development of ethnic identity in their children (Vera \& Quintana, 2004). Common cultural characteristics reported throughout the literature indicate and the length of time in the United States. Familism characterizes the Hispanic culture; family includes extendedmembers and is patriarchal innature. Machismo is another characteristic of the culture and refers to strongly defined sex roles. The father is the head of the household and is to be deferred to and respected. Men are expected to be strong, dominant, authoritarian, and are held in higher esteem than women.The mother is to care for the home and the children and is to be honored by the children. Fathers will often work multiple jobs in order to allow the mother to stay home. On the average, Hispanics have larger families than other groups, and children are normally included in most activities in which the parents participate (Zayas, Canino \& Suarez, 2001; Bevin, 2001).

There is no clear consensus on the parenting styles of Hispanic families. There are reports of permissive, authoritative, and authoritarian parenting (Julian, McKenry \& McKelvey, 1994). Several studies have found that Hispanics parents are warm, loving, and nurturing. In addition, they are less likely to use physical discipline and more likely to use verbal punishment. Similar to the Asian population, children are expected to assume additional responsibility in the family as they get older. Hispanics value independence, self-control, obedience, getting along with others, and athletic success (Ferrari, 2002; Jambunathan, Burts \& Pierce, 2000).

Implications for the Counseling Professional. Due to the amount of diversity among the Hispanic population, counselors must be careful not to generalize or that Hispanics typically have a unilateral communication style when dealing with authority. Avoiding eye contact, deference, and silence are all indications of respect for authority. Many Hispanics have strong spiritual values and may look to prayer or patron saints in times of stress or crisis (Garcia, 2001).

Due to a cultural history of oppression, Hispanics need to feel empowered to make changes in their environment. Arrendondo (2006) suggests that cognitive behavioral therapy (CBT) and reality therapy are appropriate theories to utilize in working with Hispanic families. These approaches develop skills, encourage positive decision-making, and avoid blame. CBT also emphasizes patterns of family interaction and the influence of those patterns on family interaction and dynamics. Reality therapy recognizes the need for love and belonging, which is an appropriate fit for Hispanic families based upon the strong family unit.

Like any other ethnic group that has immigrated, Hispanic families may experience culture clash among the generations. Counselors must be sensitive to this issue and carefully negotiate a solution to the conflict, while respecting cultural values. Some younger generations of Hispanics are evolving in their roles in the family, with parents sharing more of the responsibility for child rearing and living in a more egalitarian system. This may create conflict within the extended family if elders value the more traditional patriarchal system. Due to familism, it might be easy for a counselor from the Western culture to assume the family is enmeshed and attempt to create independence. This conflict in values 
could be the source of more problems (Bevin, 2001).

\section{European Americans}

European Americans include the group of individuals whose ancestors emigrated from Europe and comprise the majority culture. Most parenting studies and theories are based upon the middle class of this population. European Americans are more likely to use authoritative parenting styles characterized by inductive reasoning, providing choices for children, and encouraging independence. Using this style, a parent would provide an explanation to the child regarding why behavior is unacceptable or undesirable. The parent would then explain possible consequences if the behavior is repeated, and then acknowledge the child's freedom to choose to comply or accept the consequences. Ferrari (2002) conducted research to examine cultural patterns in parenting strategies. This research surveyed 150 parents of Hispanic, African American, and European American descent to investigate how cultural factors contributed to disciplinary techniques utilized by parents. The study found that European American parents were less likely to use verbal or physical punishment than any other group.

Anecdotal information indicates several trends among European Americans. This population tends to be more future oriented, encourages open and honest communication, and competition. Children are encouraged to actively explore and question their environment and consider numerous options when problem solving. There is less involvement with extended family than other groups, and relationships are often emotionally detached (Jambunathan, Burts \& Pierce, 2000; Hess \& Hess, 2001). European Americans value strength, self-discipline, self-control, and privacy. Education and work are viewed as the means to success and monetary gain. Families are more child-centered than other ethnic groups, and children's activities often determine family priorities (Hess \& Hess).

Implications for the Counseling Professional. European Americans set the norms and standards for the Western culture. However, there is diversity among the population dependent upon social class, educational level, and religious values. The cultural values of competition, success, and affluence are frequently the source of stress and issues within the family.

Due to the child-centered approach to family, children may be in control of the family. In an attempt to avoid being authoritarian, parents may swing to the opposite end of the spectrum and abdicate the role of authority within the family. The schedule of extra-curricular activities often over commits a family and does not allow for unstructured family time (Rosenfeld \& Wise, 2001). The stress of the family schedule may contribute to an increase in anxiety-based disorders in children and lower tolerance levels in parents (Elkind, 1998). Counselors have a difficult task tin helping European American families to find a balance in their lives.

\section{Case Study}

As mentioned previously in the article, culture clash can be experienced as children become more acculturated to the social norms of the dominant group. The following case study is an example of the conflict that can result between parent and child as a result of different levels of acculturation.

Brad Taylor was a ninth grade student in a small magnet school in a suburban area. Brad's father was African American and had been raised in the Mormon faith. His mother was from a Caribbean Island and had been raised Catholic. Both parents had very conservative upbringings with rigid rules for social behavior. Mrs. Taylor had attended Catholic school and was educated by convent nuns. She converted to the Mormon faith when she married. Brad's parents had very strict expectations for his social behavior and his school performance. Brad was an attractive and friendly young man resulting in strong social relationships. He also had a normal curiosity and attraction to girls. His social life often distracted him from academic endeavors. In addition, Brad's teachers suspected a learning disability.

As far as his social and emotional development, the school staff considered Brad to be a normal, healthy, 14-year-old male. His mother did not see things in the same manner. Some of the typical social practices of the American culture baffled her. She did not understand the practice of allowing children to sleep over at the home of a friend. She felt certain that the only reason for spending the night at someone else's home was to participate in behaviors of which parents would not approve. She insinuated that those parents who would allow a child to spend the night in his or her home do so because they intended to take advantage of that child. She did not understand why adolescents would talk to each other on the phone or want to spend time together outside of school. Time outside of school should be spent with family, at church, or completing academic work.

Mrs. Taylor was a frequent visitor to the school 
counselor's office. She was unwilling to consider any type of assessment for a learning disability. She was convinced that Brad simply was not applying himself. She considered his social behaviors to be abnormal and could not understand why he put his social life ahead of academic pursuits. After one incident in which Mrs. Taylor overheard a phone conversation with a girl, she presented unannounced in the counselor's office and was extremely emotional. She asked that Brad be called to the office so that the counselor could assist her in convincing him that "girls are evil." Her social values were based upon her own upbringing, as well as the social principles of the Mormon church.

Brad was also a frequent visitor to the school counselor. He would express his frustration with his parent's inability to understand a typical adolescent's social life in the culture in which he was living. He expressed his respect for his parent's faith; however, he did not agree with the beliefs of the Mormon faith and intended to leave the church once he was an adult. He was torn between wanting to be respectful of his parents and wanting to fit in socially.

The counselor was in a difficult situation. She could certainly see Brad's perspective and understood that he was behaving in a developmentally appropriate manner. However, she also wanted to be respectful of his parents and their values and beliefs. She wanted to encourage Brad to be compliant with his parent's rules; yet, support his exploration of his own values and belief system. Her first task was to establish a rapport with both Brad and Mrs. Taylor so that a working alliance could be formed. On several occasions, the counselor facilitated a discussion between Brad and his mother helping them each to see the other's perspective. It was important for the counselor to refrain from imposing her own ideas and beliefs upon either one. In addition, the counselor engaged Mrs. Taylor in volunteer activities on campus so that she could get to know some of the other students and have the opportunity to observe adolescent behaviors. In doing so, she recognized that Brad demonstrated a higher level of respect and academic commitment than many of his peers. She was able to observe the positive relationships that Brad had with his teachers and with his peers. She began to see her son in a different light. She never agreed to an academic assessment, but she did see the struggles and agreed to additional tutoring.

As the counselor developed a positive and trusting relationship with Mrs. Taylor, it provided the opportunity to educate her on normal social behaviors of adolescents in the Western culture. The counselor also asked Mrs. Taylor to educate her on the social practices of her culture. This provided the opportunity to discuss commonalities and differences. Mrs. Taylor slowly became very aware of how the differences in her expectations and the reality of his social world were affecting Brad. The counselor helped Mrs. Taylor to find areas that were negotiable and areas that were non-negotiable. In addition, she assisted Brad and Mrs. Taylor in reaching some compromises with which they both felt comfortable. Brad and his mom continued to experience some of the typical conflicts that occur between a parent and child during adolescence. However, the intensity of those conflicts declined as a result of resolving the issues related to culture clash. When Brad graduated from high school, he found he was more accepting of the Mormon beliefs. He was not certain as to whether or not he would continue in the faith and still wanted to explore other religions on his own. Mrs. Taylor's anxiety level had decreased, and she and Brad had a much better relationship as a result of the work of a culturally sensitive counselor.

\section{Conclusion}

The counseling professional must be culturally responsive in order to be effective in working with diverse populations. Cultural values must be considered in determining the problem, the goals for treatment, and the treatment process. In addition to working with a culturally diverse population, counselors are dealing with different levels of acculturation and atypical family systems. Intercultural families, blended families,

single parents, and same-sex parents each present challenges for the treatment process. Counselors must educate themselves beyond traditional counseling theories and techniques, and develop a comprehensive repertoire of tools to be effective with clients. However, the most important thing for counselors to remember is that regardless of cultural background, the client must be viewed as an individual. Developing a therapeutic relationship involves getting to know and understand your client in order to determine which cultural generalizations may apply and which are inappropriate for that individual. 


\section{References}

Arredondo, P. (2006). Multicultural competencies and family therapy strategies with Latino families. In R. L. Smith, \& R. E. Montilla (Eds.), Counseling and family therapy with Latino populations (pp.77-96). New York: Routledge.

Baumrind, D. (1991). The influence of parent style on adolescent competence and substance use. Journal of Early Adolescence, 11(1), 56-95.

Bevin, T. (2001). Parenting in Cuban American families. In N. B. Webb (Ed.), Culturally diverse parent-child and family relationships: A guide for social workers and other practitioners (pp. 181-201). New York: Columbia University Press.

Blue, H. C., \& Griffith, E. E. H. (2001). The African American. In W. S. Tseng, \& J. Streltzer (Eds.), Culture and psychotherapy: A guide to clinical practice (pp.137-155). Washington, DC: American Psychiatric Press.

Chao, R. K. (1994). Beyond parental control and authoritarian parenting style: Understanding Chinese parenting through the cultural notion of training. Child Development, 65, 1111-1119.

Dana, R. H. (1998). Understanding cultural identity in intervention and assessment. Thousand Oaks, CA: Sage.

Darling, N. (1999). Parenting styles and its correlates. ERIC Clearinghouse on Elementary and Early Childhood Education. (ERIC Document Reproduction Service No. ED427896)

Elkind, D. (1998). Ties that stress: The new family imbalance. Boston, MA: Harvard University Press.

Ferrari, A. M. (2002). The impact of culture upon child rearing practices and definitions of maltreatment. Child Abuse and Neglect, 26, 793-813.

Garcia, E. C, (2001). Parenting in Mexican American families. In N. B. Webb (Ed.). Culturally diverse parent-child and family relationships: A guide for social workers and other practitioners (pp 157-179). New York: Columbia University Press.

Hess, P. M., \& Hess. H. J. (2001). Parenting in European American/White families. In N. B. Webb (Ed.). Culturally diverse parent-child and family relationships: A guide for social workers and other practitioners (pp 307-333). New York: Columbia University Press.

Hines, P. M, \& Boyd-Franklin, N. (1996). African American families. In M. McGoldrick, J. Giordano, \& J.K. Pearce (Eds.), Ethnicity and family therapy (pp. 66-84). New York: Guilford Press.

Jambunathan, S., Burts, D. C., \& Pierce, S. (2000). Comparisons of parenting attitudes among five ethnic groups in the United States. Journal of Comparative Family Studies, 31 (4), 395-406.

Julian. T. W., McKenry, P. C., \& McKelvey, M. W. (1994). Cultural variations in parenting: Perceptions of Caucasian, African American, Hispanic, and Asian-American parents. Family Relations, 43(1), 30-37. 


\section{References}

Karraker, M.W., \& Grachowski, J. R. (2006). Families with futures: A survey of family studies for the twenty-first century. New York: Routledge.

Lee, E. (1997). Working with Asian Americans. New York: Guilford.

Lee, E. (1996). Asian American families. An overview. In M. McGoldrick, J. Giordano, \& J.K. Pearce (Eds.), Ethnicity and family therapy (pp. 227-248). New York: Guilford Press.

Lee, W. M., Blando, J. A., Mizelle, N. D., \& Orozco, G. L. (2007). Introduction to multicultural counseling for the helping professionals. New York: Routledge.

McAdoo, H. P. (2001). Parent and child relationships in African American families. . In N. B. Webb (Ed.). Culturally diverse parent-child and family relationships: A guide for social workers and other practitioners (pp 89-106). New York: Columbia University Press.

Mosby, L., Rawls, A. W., Meehan, A. J., Mays, E., \& Pettinari, C. J. (1999). Troubles in interracial talk about discipline: An examination of African American child rearing narratives. Journal of Comparative Family Studies, 30(3), $489-521$.

Richardson, B. L. (1991). Utilizing the resources of the African American church: Strategies for counseling professionals. In C. C. Lee, \& B. L. Richardson (Eds.), Multicultural issues in counseling: New approaches to diversity (pp. 65-75). Alexandria, VA: American Association for Counseling and Development.

Richardson, B. L, \& June, L. N. (2006). Developing effective partnerships in order to utilize and maximize the resources of the African American church: Strategies and tools for counseling professionals. In C. C. Lee (Ed.), Multicultural issues in counseling: New approaches to diversity (3rd ed.) (pp. 113-124). Alexandria, VA: American Counseling Association.

Rosenfeld, A., \& Wise, N. (2001). The over scheduled child: Avoiding the hyper-parenting trap. New York: St. Martins.

Stewart, S. M., Bond, M. H., Kennard, B. D., Ho, L. M., \& Zaman, R. M. (2002). Does the Chinese construct of guan export to the West? International Journal of Psychology, 37(2), 74-82.

Vera, E. M., \& Quintana, S. M. (2004). Ethnic identity development in Chicana/o youth. In R. J. Velasquez, L. M. Arellano, \& B. W. McNeill (Eds.), The handbook of Chicana/o psychology and mental health (pp.43-59. Mahwah, NJ: Lawrence Erlbaum.

Webb, N. B. (2001). Culturally diverse parent-child and family relationships: A guide for social workers and other practitioners. New York: Columbia University Press.

Zayas, L. H., Canino, I., \& Suarez, Z. E. (2001). Parenting in mainland Puerto Rico families. In N. B. Webb (Ed.). Culturally diverse parent-child and family relationships: A guide for social workers and other practitioners (pp 133-156). New York: Columbia University Press. 